\title{
The Effect of Software Team Personality Composition on Learning and Performance: Making the "Dream" Team
}

\author{
Greg Anderson \\ Brigham Young University \\ profganderson@gmail.com
}

\author{
Mark J. Keith \\ Brigham Young University \\ mark.keith@gmail.com
}

\author{
Julianne Francisco \\ Brigham Young University \\ julianne.francisco@gmail.com
}

\author{
Sarah Fox \\ Brigham Young University \\ knottsarah@gmail.com
}

\begin{abstract}
Optimizing work team composition in organizational and educational environments is an important task toward maximizing performance. Social science research has revealed that personality trait composition influences team cohesion and performance. However, this research has not been well-adapted into the IS context. In addition, prior research demonstrates how individual personality traits impact teams, but fails to appropriately characterize overall team personality composition. We expand this research by 1) characterizing holistic personality compositions, and 2) examining team learning in addition to performance in the IS context. We draw from theory on team performance and "Big 5" trait composition. Results demonstrate that teams comprised of homogenous versus heterogeneous personality compositions differ in their performance and learning. The primary implication of this research is that teams can benefit from a priori personality measurements and directed composition. Initially, optimal learning and effectiveness comes from homogenous teams. However, this may change over time.
\end{abstract}

\section{Introduction}

The most fundamental part of any business, academic, or societal institution are the people. Success or failure hinges on their ability to work together and produce quality work [65]. However, teams are not just combined skills and experience. Teams are made up of individual people with individual personalities which are known to impact team performance [50, 65]. Personalities define many of the psychological factors of teams, such as how each person interacts with others and the different roles they take on within that team [33].

Team performance is a relevant issue in the information systems (IS) discipline because IS projects and many other types of work happen in teams [64]. Teams are important in IS not only because they are so often used in organizations, but also because IS academic programs predominantly use teams for coursework and general learning [30].
Team cohesion is, perhaps, the dominant theory used to explain and predict team effectiveness/performance $[1,7,15,16]$. However, performance is not the only important outcome from teamwork. Teams are often composed in ways that facilitate learning [22], and learning in teams is greatly affected by the composition of individual personalities in the team [50]. For example, 77 percent of employers say that soft skills, including personality traits, are just as important as the specific skills needed to perform a job function [13]. Therefore, research that explains the exact role of personality traits in team learning and performance is valuable to employers.

Currently, there is some research on the role of individual personality in team effectiveness in software teams [54, 12, 19, 20]. However, this is problematic because personality traits are not independent from each other [28]. Overall individual personalities are comprised of a variety of traits. Therefore, if managers attempt to optimize a team around one "positive" personality trait, they may inadvertently combine other traits which may have negative effects. Therefore, the practical implications of existing research are somewhat limited. Without firing/hiring employees, a manager cannot simply add more "agreeableness" to one team without reducing the agreeableness of other teams. On the other hand, a manager can affect the homo/heterogeneity of team personality compositions by grouping similar or dissimilar individual personalities into teams. While several good studies have examined the effects of team personality variance (i.e. homogeneity of the individual personalities on the team) [32, 42, 5], none have manipulated team personality variance in an experiment to establish causality to the best of our knowledge.

The software development environment also creates a unique context of study. Because of constant advances in the discipline and the need to integrate a variety of code platforms, the practice of software development is knowledge-intensive and its success hinges on the effective storage, development, and dissemination of knowledge among team members [2]. In other words, successful software development teams need to learn over time [3]. While effectiveness is the short-term 
priority of all teams, learning must be a long-term priority to maintain competitive advantages. Therefore, studies of team personality should consider both shortterm (effectiveness) and long-term (learning) goals. Yet, currently, no research in the IS discipline characterizes the team personality composition [e.g., 50] construct nor how it affects both effectiveness and learning. In summary, our research questions are: Should teams be comprised of those with similar or diverse personalities and what effect will team personality composition have on both individual learning and team effectiveness?

While these questions may be asked of a variety of teams, our research is specific to the IS and software development context because we measure learning as the improvement in IS creative self-efficacy (CreaSE) [49] which is a measure of an individual's confidence in their ability to solve business problems with information technology. We also draw from theory on the "Big 5" personality traits (agreeableness, extraversion, neuroticism, openness to experience, and conscientiousness) [40], but also, how these traits can be characterized at the team level [50]. We perform a laboratory experiment with 34 student software teams (total of 129 participants) who were randomly assigned to groups of 3-4 members with either 1) similar personality compositions or, 2) diverse personality compositions. Our results indicate that teams with similar personalities had greater learning and effectiveness.

\section{Literature and Theory}

In this section, we build our theoretical model. The core of the model comes from the results of several meta-analytical theoretical reviews of the effects of team personality compositions and their outcomes [42, 32]. Figure 1 is an adaptation of their findings. In general, the research findings on team personality composition indicate that team personalities affect team processes which, in turn affect team effectiveness. Logically, individual team member personalities combine to produce a team personality. In addition, individual personalities lead to behaviors which affect team processes and effectiveness. The focus of this research will be on improving the measurement of team personality composition and the conceptualization of team processes. The effects of team member personality and team member behaviors are well-establish in prior literature $[42,32]$ and are not included in this study. In the remainder of this section, we review the relevant theory for team personality composition, processes, and effectiveness and apply it to the software development team context.

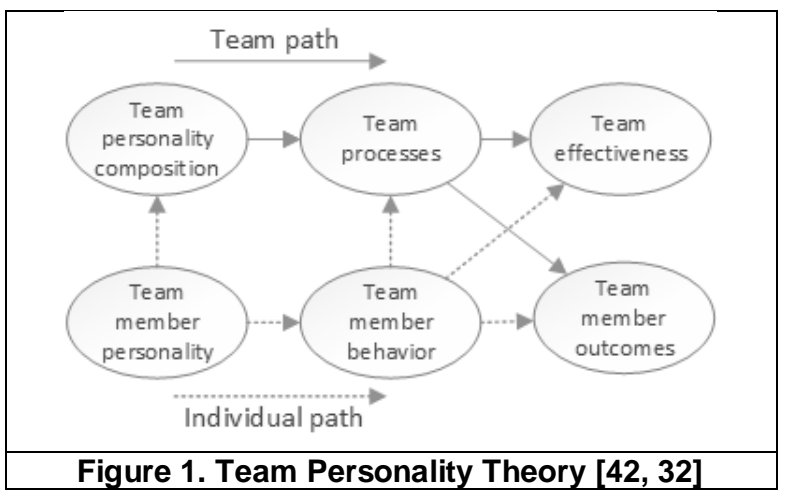

\subsection{Team Member Personality: "Big 5" Traits}

To model team personality composition, we begin by explaining individual personality. The "Big 5" personality traits are a model of human personality based on a factor analysis of validated personality-based survey items. The resulting model includes 1) extraversion, 2) agreeableness, 3) conscientiousness, 4) neuroticism, and 5) openness to experience [28]. Personality traits refer to relatively enduring characteristics of the individual that are acquired during development and are relatively resistant to change [11].

2.1.1. Extraversion. Extraversion is defined by excitability and high amounts of emotional expressiveness. Individuals who are high in extraversion are generally sociable and talkative. They enjoy big crowds and draw their energy from social situations. Those who score low on extraversion are considered introverts. They are more reserved and deliberate in nature. They tend to draw energy from time alone.

2.1.2. Agreeableness. Agreeableness is exemplified by kindness, affection, and humility. Those who score high in agreeableness are usually very moral and sincere people. They tend to be more cooperative than combative and will smooth things over for the sake of peace. Those who score low in agreeableness can be very competitive, sometimes manipulative, and place self-interest above getting along with others.

2.1.3. Conscientiousness. Conscientiousness is defined as high levels of thoughtfulness and organization. Those who score high in conscientiousness tend to have good impulse control and are very goal-directed. They can also be very cautious. Those who are low in conscientiousness are usually very colorful people and act on their impulses. They can be accused of unreliability and a lack of ambition. 
2.1.4. Neuroticism. Neuroticism is also known as emotional stability. It is defined as mood swings and a low tolerance for stress. Those who score high in neuroticism are prone to bouts of sadness, anxiety, irritability, and vulnerability. Those who score low in neuroticism are emotionally stable and resilient, calm, and handle stress well.

2.1.5. Openness to Experience. A person who exhibits traits in the openness to experience factor is defined by having a broad range of interests, being adventurous, and creative. Those who score high on openness are imaginative, bring new insights to groups, and enjoy variety. Those who score low on openness are more traditional, down-to-earth individuals. They can resist change and may struggle with abstract thinking.

2.1.6. Team Personality Composition. These five factors have been linked to a very wide variety of social, individual, and organizational outcomes. However, researchers have had a difficult time operationalizing these Big 5 traits at the team level [32]. There have been three primary characterizations of team personality [32].

The most common technique has been to simply calculate elevation, or mean scores, for each of the Big 5 traits. This technique assumes that the collective amount of each characteristic can be pooled into an overall team characteristic.

The second technique involves measuring the variability of the individual personality traits. This can be operationalized as 1) the variances of traits, 2) the range of each trait, and 3) the proportion of team members possessing a particular trait.

The third way to characterize team personality is based on the minimum and maximum scores within the team. This is because one team member can significantly affect the team outcomes [5]. It is measured simply by using the highest and lowest personality scores of any member of a team.

Based on the recommendations from meta-analyses $[32,50]$, we use both of the first two methods in this study: the collective team personality score (used only as a covariate) and the personality variance among team members (used as the primary manipulation of our experiment). While the collective team personality score has often been used to assess the effect of personality on software team performance [e.g., 54, 12, 19, 20], there is little, if any, research on how the variance in team personality affects software team outcomes.

This is a significant gap because organizations desire all of their teams to be effective. Therefore, they cannot simply form a new project team by taking all of the employees who are highest in a particular personality trait. Otherwise, some teams will be less successful than others. However, managers can control the variance in personalities across all teams and optimize them for different outcomes. For example, some teams may be optimized for learning while others are optimized for performance. Therefore, we will measure elevation as a covariate and manipulate variability in our experiment. While some studies have examined variability [32, 42], none (to the best of our knowledge) have manipulated it in team experiments to establish causality. By doing so, we can give managers strong advice on how to take advantage of the personalities they have among potential team members.

To help us hypothesize the effects of team personality variance, we next review research on the outcomes of learning and effectiveness and link them to personality research.

\subsection{Team Processes and Team Effectiveness}

In general, research on team personality has examined two primary outcomes [32]: task relationships and team performance which [42] conceptualize as team processes and team effectiveness. Team effectiveness is often measured in terms of supervisor ratings [5], improvement in quantitative scores (e.g. sales, satisfaction) [23], or grades in a classroom setting [6].

Team processes have been operationalized in a variety of ways. Group cohesion is a concept that includes sub-components of both group relationships and performance. Group cohesion also happens to be one of the dominant theories used to explain team performance $[41,24,18,10,1,15,56]$ - making it an ideal operationalization of "team processes" in personality studies [7, 62]. A cohesive group is one in which members are drawn towards one another and desire to remain a part of the group [17]. There are two dimensions to group cohesion: social commitment and task commitment $[25,14,46]$. Social commitment is the level of motivation to develop and maintain group social interaction. Task commitment includes a common level of motivation to complete the team's objective and whether team members cooperate well and feel like they can contribute [16]. Figure 2 visualizes the multidimensional group cohesion construct.

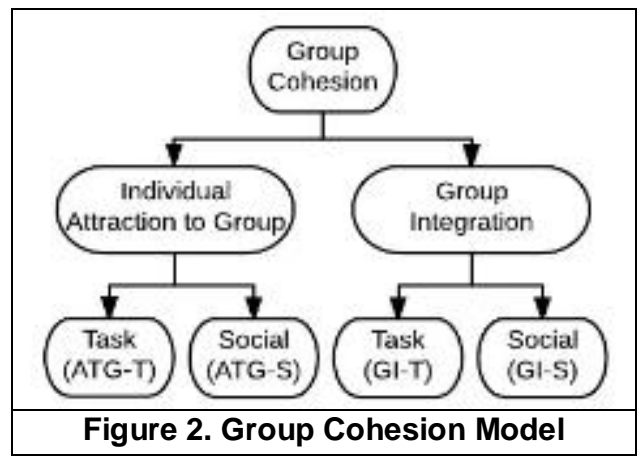


The GI-T and GI-S represent the "us", "our", and "we" individual perceptions of the group such as the closeness, similarity and bonding. The ATG-T and ATG-S represent the "I", "my", and "me" individual perceptions of self and the motives to remain in the group [15]. The "S" represents the social relationships within the group and 31 how an individual views the group as a social aspect. The "T" identifies the individual's perception towards achieving a goal.

In summary, group cohesion includes both task (GIT and ATG-T) and relationship (ATG-S and GI-S) subconstructs making it an ideal way to characterize the effects of team personality based on prior theory [32]. Therefore, we adopt group cohesion, as well as task performance, as dependent variables in our study as indicated in Figure 1.

2.2.1. Prior Research on Personality and Cohesion. To be clear, ours is not the first study to use group cohesion constructs as endogenous variables to personality measures. Many good studies and reviews exist that can demonstrate the effects of individual Big 5 traits on cohesion and/or performance [62, 57, 50].

Perhaps the most closely relevant study to ours, van Vianen et al. [62] found that team personality, measured all three ways suggested by Halfhill et al. [32] (elevation ["means"], variability, minimums, and maximums), did have limited effects on group cohesion and task performance. In particular, the team elevation of each Big 5 trait led to positive effects on both task cohesion (including agreeableness and conscientiousness) and social cohesion (including extraversion and emotional stability [the opposite of neuroticism]). In addition, team variance on each personality trait had a negative effect on either group cohesion and/or performance in at least one of the three contexts they studied. While these personality studies do not provide much theoretical explanation for the effects of team personality variance, there is evidence in related fields that personality conflicts can lead to poor conflict resolution and lower relationship satisfaction [55]. Therefore:

\section{H1: Team personality variance negatively affects group cohesion.}

A common theme in the research is that each trait is analyzed individually. For example, elevation (mean), variability (variance), maximum, and minimum are calculated separately for each trait. However, the Big 5 traits are not fully independent personality characteristics that exist in isolation from each other [28]. There is some level of collinearly among them and overall personality is represented as a combination of all five. For example, it is commonly found that a team's collective (i.e. "mean score") conscientiousness leads to greater social cohesion [42]. However, if a manager optimizes for conscientiousness, he or she may simultaneously be optimizing for high neuroticism which has negative effects on team outcomes [50, 32, 42]. Therefore, all five traits need to be conceptualized into a single elevation and variability score. Although several good meta-analytic studies exist that evaluate the effect of personality elevation and variability on group cohesion and/or effectiveness [50, 32, 42], they examine these measures trait-by-trait without combining them into a single composite score. As a result, we will implement a more appropriate measure of collective personality and personality variance (explained in the Methodology section).

There are three other important reasons to continue with our research objective. First, none of the studies that include a variance measure of team personality are in the context of software development or closely related topics and, therefore, may not generalize well to the information systems field. To be fair, studies of personality in software teams do exist, but they are based on older personality measures that have been dropped in favor of the Big 5 model [e.g., 54]. Second, although team personality composition has been examined, no research that we are aware of has actually manipulated team personality variability to establish its causal effect on team processes and effectiveness. Third, there are other important outcomes of team personality composition that are relevant to software development teams that need to be examined which haven't been in prior research - namely the individual learning that takes place in software development teams.

\subsection{Team Member Learning: CreaSE}

Although team performance is always a priority dependent variable in the short run, organizations realize that team members also need to grow and learn in order to maximize long-term performance [38, 29]. Learning is particularly important in software development teams where creativity and experience are primary factors for performance over time [8, 45]. Furthermore, agreeableness, extraversion, conscientiousness, neuroticism, and openness to experience each affect learning and learning orientation $[21,11]$. Therefore, we need to characterize a relevant definition of learning in software development teams to examine the effects of team personality.

Creativity has been identified as one of the most important characteristics of successful software developers and information systems (IS) practitioners $[31,35,60,47,8,45,49]$ and, therefore, is a prime topic in academic IS curriculums [36, 37]. Management researchers have also argued that one's confidence in 
their ability to find creative solutions is as, or more, important as their actual creative abilities. This belief in one's ability to solve unstructured problems requiring creativity is referred to as creative self-efficacy [29, 52, 59]. Most recently, IS researchers have adapted this construct to measure IS creative self-efficacy (CreaSE) which refers to, "....an individual's belief in their ability to develop creative solutions to new or unstructured business problems through the development of information systems that support business process and the people who execute them" [49, pg. 5].

Based on core theory on human creativity [34], CreaSE is a second-order formative construct based on five independent factors [49]: 1) affect, 2) business skills, 3) intelligence, 4) people skills, and 5) technology training. Affect refers to our emotions, moods, and attitude [9] toward creative problem solving which has a significant effect on our creative performance. For example, negative affect can reduce our "flexible thinking" and problem solving capabilities on complex tasks [4]. Business skills are a person's knowledge about the business domain they are working in including processes, strategies, and management. Intelligence is the factor that changes the least and refers to the cognitive ability for creativity a person is innately born with. People skills are a person's ability to collaborate effectively with others on a team and combine the good ideas from others into their own problems solving framework. Finally, technology training refers to the hard technology skills that a person has, such as programming, data analytics, and computer systems, which will be combined and implemented in creative ways to solve IS problems.

CreaSE has been positioned as a primary outcome variable measuring the effectiveness of IS students and practitioners [49]. Therefore, we characterize a software development team member's learning as their improvement in CreaSE over time. Because variability in team personalities may lead to conflict [55] and lower group cohesion [62], we hypothesize:

H2: Team personality variance negatively affects team member improvements in CreaSE.

Figure 3 visualizes our research model based on implementing the theoretical model in Figure 1 in the software development context. We have darkened the lines of those constructs that we either improve the measurement for (team personality composition) or evaluate new for this study (learning). In our model, we use the term "cross-trait" to indicate that we will measure and characterize all Big 5 traits into a single score in our methodology. Although we will test every relationship specified in Figure 3, we have only hypothesized those which are unique to, and a contribution made by, this study.

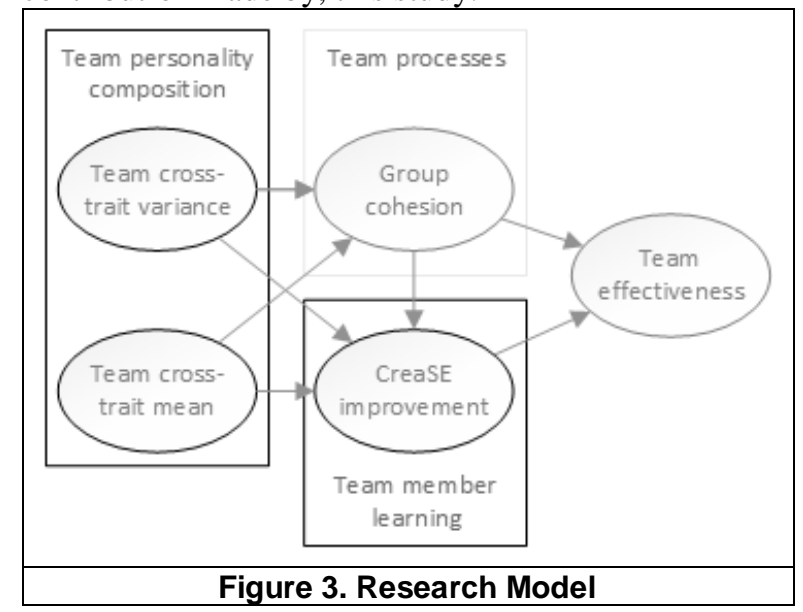

\section{Methodology}

To test our model, we conducted a laboratory experiment with a class of 129 students enrolled in a Java-based software development course who were assigned team-based projects. A laboratory experiment was necessary in order to have the ability to manipulate team personality composition. To be clear, we do not mean that we manipulated individual personalities, but that we captured individual personalities with a pre-test and then randomly assigned them to groups of high personality variance versus low personality variance treatments. In other words, we implemented a 2treatment, between-groups design where teams were comprised of either homogenous or heterogeneous personality composites. The exact procedures for this methodology are described next.

\subsection{Procedures}

At the beginning of the course, students were given a pre-survey measuring the Big 5 personality traits (agreeableness, conscientiousness, extraversion, openness to experience, and neuroticism) based on Goldberg et al.'s validated instrument [28] on a 5-point Likert scale from $1=$ strongly disagree to $5=$ strongly agree. In addition, we measured a baseline score of their CreaSE using the validated instrument [49] so that their improvement in CreaSE (representing learning) could be calculated at the end of the course. We did not capture group cohesion at this time because their groups did not yet exist. In addition, theoretically, there should be no level of cohesion at the beginning of a team formation.

Next, using maximum likelihood extraction with promax rotation, we performed a factor analysis of the Big 5 measurement results to confirm that each item truly measured its intended construct. We removed one item from the conscientiousness construct and one from 
neuroticism to produce an optimal measurement model and recorded the final factor scores.

Next, in order to characterize a composite personality score for each participant that would be based on all five traits (as opposed to examining each trait individually as in prior research [42, 32]), we performed a k-means cluster analysis. A gap statistic [58] was calculated for every combination of clusters from 2 to 25 which determined that the data best fit into two clusters. We then recorded the Euclidean distance for each participant representing the closeness of their score across all five traits to the center of the nearest of the two clusters. This allowed us to characterize team members' overall personality as well as how closely they fit within that personality. Figure 4 illustrates the actual average personality trait scores between the two clusters. Note: $\mathrm{EXT}=$ extraversion, $\mathrm{AGR}=$ agreeableness, $\mathrm{CON}=$ conscientiousness, $\mathrm{NEU}=$ neuroticism, $\mathrm{OPE}=$ openness to experience.

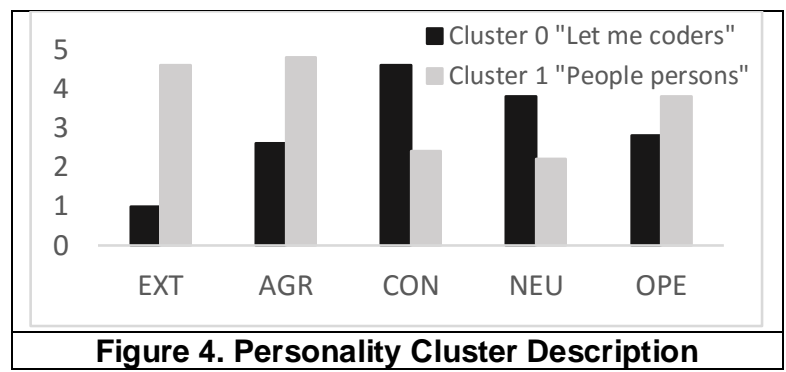

Analysis of variance (ANOVA) tests reveal that extraversion $(F=134.93, \mathrm{p}<0.001)$, agreeableness $(F$ $=58.98, \mathrm{p}<0.001)$, neuroticism $(F=4.72, \mathrm{p}=0.032)$, and openness to experience $(F=64.96, \mathrm{p}<0.001)$ each significantly differentiated the two clusters. Conscientiousness, although quite different between the two clusters, did not $(F=0.692, \mathrm{p}=0.407)$. In summary, Cluster 1 represents those who are highly extraverted, agreeable, and open to experiences, while low in neuroticism. A person in Cluster $1(n=51)$ is more of a "people person" who likes collaboration and working with others. Cluster $0(n=78)$ represents those who are low in extraversion and agreeableness, and to a lesser degree, low in openness to experience. Yet they are highly neurotic. These can, perhaps, be described as those who want to work independently from others. We call them the "just let me coders."

3.3.1. Manipulation. Once every participant had been classified into an overall personality type, we manipulated the variability of team personality composite by randomly assigned (with stratification into equal sized teams) them into teams of four that were comprised of individuals of either a) the same personality cluster, or b) two from each personality cluster. In other words, they were randomly assigned to either homogeneous (based on personality) teams or heterogeneous teams. However, because there was not an even number of participants in each personality cluster, we had to kept the number of participants equal in the heterogeneous treatment to balance the teams (two members of each personality type) while having different numbers of homogenous teams (see Table 1).

\begin{tabular}{|l|c|c|c|}
\hline \multicolumn{4}{|c|}{ Table 1. Number of Participants } \\
\hline & $\begin{array}{c}\text { Cluster 0 } \\
\text { "let me } \\
\text { coders" }\end{array}$ & $\begin{array}{c}\text { Cluster 1 } \\
\text { "people } \\
\text { persons" }\end{array}$ & Teams \\
\hline Homogeneous & 48 & 21 & 18 combined \\
\hline Heterogeneous & 30 & 30 & 16 combined \\
\hline
\end{tabular}

At the end of the semester, we collected students' effectiveness data, which was their grades from three team-based projects during the semester. All students participated in the same assignments under the same professor, with the same resources available to them. We also administered another survey to capture group cohesion based on validated instruments [16, 14, 15]. This survey also collected the CreaSE instrument again to measure learning and improvement in their confidence in writing code to solve business problems.

\section{Results}

Figure 5 depicts the differences in group cohesion developed for each treatment. Figure 6 depicts the learning that took place over the semester represented as the improvement in the overall CreaSE score. Figure 7 depicts the three team based projects used to calculate their team effectiveness score. The projects are listed in the chronological order they were delivered in.
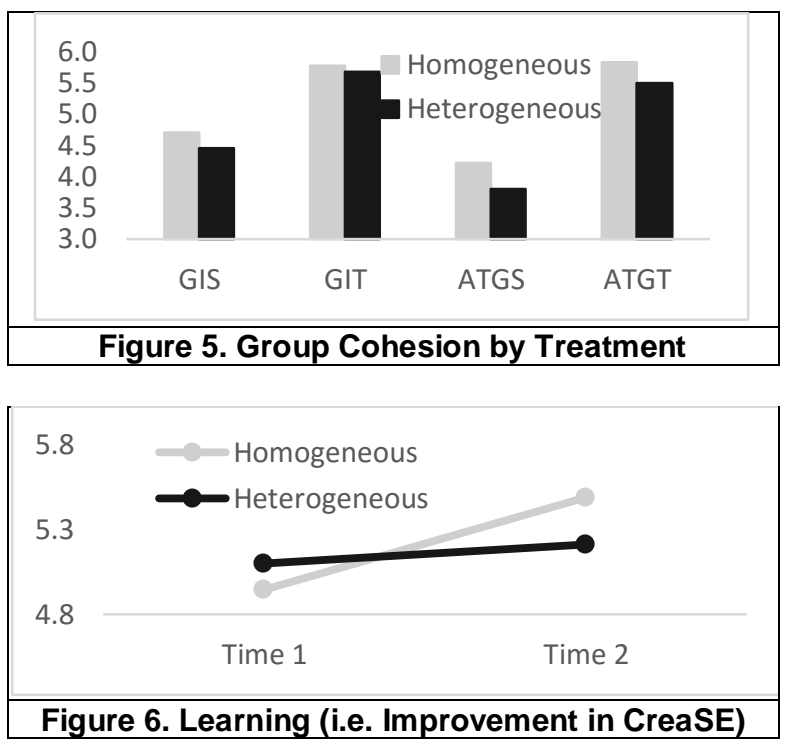


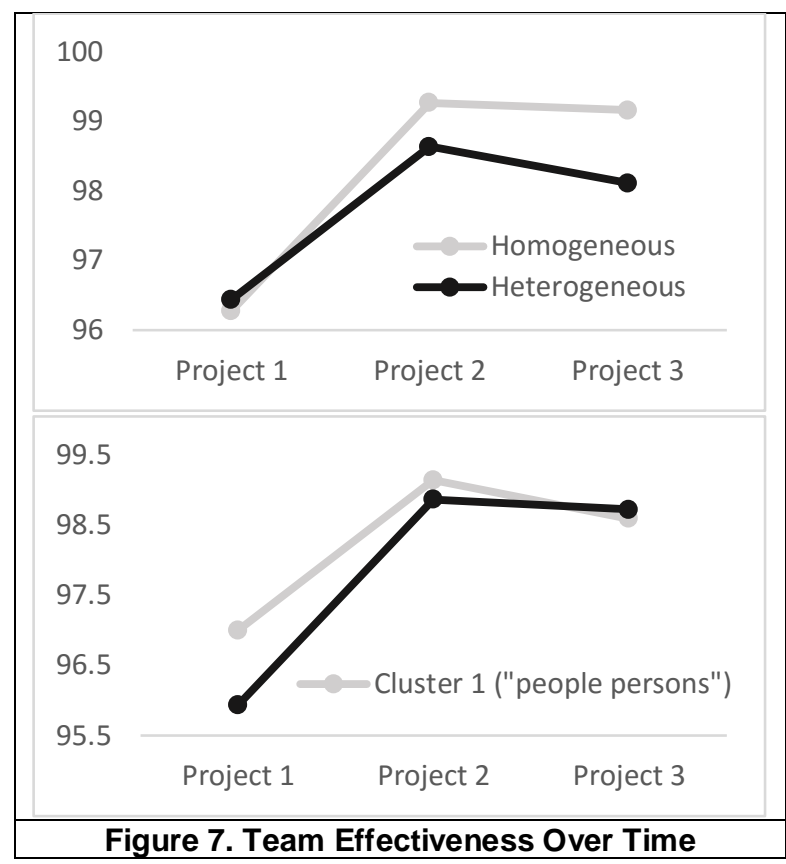

Table 2 summarizes the results of a multivariate ANOVA using the treatment and the cluster as factors with the Euclidean distance from the cluster and age as covariates. To better understand the results, we broke apart the group cohesion and CreaSE scales into their sub constructs (as is common [e.g., 7, 62]). For simplicity, we include the only significant effects of Cluster and all effects of Treatment. The group cohesion and CreaSE scores used in this analysis are based on averages of the items representing each construct. Although we manipulated personality composition at the team level, we analyze the MANOVA at the individual level because learning (CreaSE) is an individual construct. Analyzing team effects on individual constructs is common in studies of teams and learning $[48,39]$.

Table 2. Multivariate ANOVA Results

\begin{tabular}{|c|l|r|r|r|}
\hline \multicolumn{5}{|c|}{ Table 2. Multivariate ANOVA Results } \\
\hline Factor & \multicolumn{1}{|c|}{ DV } & Mean square & \multicolumn{1}{c|}{ F } & p-value \\
\hline Cluster & Effectiveness & 5.655 & 3.172 & 0.077 \\
\hline \multirow{5}{*}{ Treatment } & GIS & 1.863 & 3.675 & 0.058 \\
\cline { 2 - 5 } & GIT & 0.440 & 0.532 & 0.467 \\
\cline { 2 - 5 } & ATGS & 5.737 & 5.008 & 0.027 \\
\cline { 2 - 5 } & ATGT & 3.250 & 5.658 & 0.019 \\
\cline { 2 - 5 } & CreaSE_INT & 5.261 & 4.793 & 0.030 \\
\cline { 2 - 5 } & CreaSE_BUS & 9.188 & 7.752 & 0.006 \\
\cline { 2 - 5 } & CreaSE_AFF & 0.709 & 1.793 & 0.183 \\
\cline { 2 - 5 } & CreaSE_PEO & 5.890 & 6.017 & 0.016 \\
\cline { 2 - 5 } & CreaSE_TEC & 6.913 & 5.785 & 0.018 \\
\cline { 2 - 5 } & Effectiveness & 15.842 & 8.886 & 0.003 \\
\hline
\end{tabular}

In summary, there was a significant effect of the treatment on learning. Particularly, participants that were in teams with low variability (homogeneous teams) in composite team personality were able to learn more in the same amount of time than high variability teams. However, Table 2 reveals greater detail. This improvement in CreaSE occurred for the intellect, business knowledge/skills, people skills, and technology skills sub-constructs, but being in a homogeneous group did not help affect: their attitude toward creative problem solving. In addition, those in homogeneous teams developed better group cohesion attitudes (ATGS and ATGT). Lastly, those whose personalities placed them in Cluster 1 (the "people persons") performed marginally better than those in Cluster 0; but this effect appeared to disappear over time. More significantly, those in homogeneous teams performed better than those in heterogeneous groups; and this effect increased over time.

\subsection{Structural Equation Model}

While the MANOVA allowed us to test individual relationships, it does not allow us to test the entire path model in Figure 3. Therefore, we also analyzed a structural equation model (SEM) using SmartPLS 3 [53]. The advantage of PLS SEM is that it allows us to model second order formative constructs appropriately $[26,43]$. Group cohesion is a second-order reflective construct which we analyzed by first calculating the latent factor scores for each of the sub constructs and then used those factor scores as indicators of a reflective construct representing the second-order group cohesion factor [e.g., 63]. Similarly, CreaSE was modeled as a second-order formative construct in the same manner except that the latent factor scores for the sub constructs were treated as formative indicators of the second-order CreaSE construct as specified in prior research [49].

Before testing hypotheses, we first analyzed the measurement properties of the latent reflective subconstructs. This includes testing for reliability, convergent validity, discriminant validity, multicollinearity. We tested each of these measurement properties using the latest techniques [26, 27] and found no issues with the measurement. We did not test for common methods bias because our dependent variables were measured separately and uniquely from our independent variables making the issue irrelevant to our data $[44,51]$.

Table 3 summarizes the results of the PLS algorithm. Significance was tested using 1000 samples of a bootstrapping procedure. In addition to testing the theoretical model in Figure 3, we also controlled for gender. We did not control for age or ethnicity as the class was very homogenous. 


\begin{tabular}{|c|c|c|c|}
\hline \multicolumn{4}{|l|}{ Table 3. Results of PLS Analysis } \\
\hline \begin{tabular}{|l|} 
Relationship \\
\end{tabular} & $B$ & $t$-stat & $p$-value \\
\hline Treatment -> Cohesion & $\mid-0.22$ & 2.58 & 0.005 \\
\hline Treatment -> CreaSE (learning) & -0.20 & 3.08 & 0.001 \\
\hline Treatment -> Effectiveness & -0.27 & 2.96 & 0.002 \\
\hline Cluster -> Cohesion & $\mid-0.03$ & 0.37 & 0.357 \\
\hline Cluster -> CreaSE (learning) & 0.09 & 1.41 & 0.079 \\
\hline Cluster -> Effectiveness & -0.15 & 1.64 & 0.051 \\
\hline Cohesion -> CreaSE (learning) & 0.18 & 2.14 & 0.017 \\
\hline Cohesion -> Effectiveness & 0.34 & 4.45 & 0.000 \\
\hline CreaSE (learning) -> Effectiveness & 0.06 & 0.60 & 0.275 \\
\hline Gender -> Cohesion & 0.19 & 2.04 & 0.021 \\
\hline Gender -> CreaSE (learning) & 0.00 & 0.01 & 0.497 \\
\hline Effectivene & -0.14 & 1.76 & 0.039 \\
\hline
\end{tabular}

\section{Discussion}

In summary, teams comprised of homogeneous personalities develop greater cohesion, greater confidence in their ability to execute creative problem solving (CreaSE), and greater effectiveness. Interestingly, while controlling for team personality variability, we found that an individual's personality cluster made a difference in effectiveness. Our cluster of "just let me coders" are more effective, but they may develop less confidence in their abilities than our cluster of "people persons." As expected, group cohesion improves performance, but learning has no effect on performance. Additionally, gender also has little effect on cohesion and effectiveness, and no effect on learning.

\subsection{Implications}

The primary implication of this research is that software development teams can be positively affected by 1) measuring individual personality, 2) clustering individuals into personality types, and 3) placing them in teams of homogenous personalities.

The theory behind this implication is that greater learning and team effectiveness occurs when conflicts are minimized. This should not imply that conflict is always bad as organization research has pointed out [61]. However, at least in the early stages of team formation and learning, reducing distractions and conflicts that arise due to personality differences has obvious benefits.

Interestingly, we performed a post-hoc analysis to detect interaction effects between the treatment and cluster. A significant effect was found $(B=-0.12, p<$ $0.05)$ meaning that being in a group of homogenous personalities was significantly more important for Cluster 0 ("let me coders"). This is not surprising since this cluster was lower in agreeableness, extraversion, and openness to experience while higher in neuroticism. These were more likely to develop conflicts because of their personality types.

\subsection{Limitations and Future Research}

This study does have some limitations. The experiment was conducted on a small dataset of students comprised of just 34 teams made up of 129 students. Naturally, our effects may be different in real software development organizations. Despite this, our implications are still very significant for IS academic programs that are motivated to maximize students' learning. IS programs should also measure personalities and optimize teams for improvements in CreaSE. However, a clear opportunity for future research is to replicate our study in a real business environment which would produce more confidence for managers in the results.

Another limitation and opportunity is that the students in our experiment were programming novices. For most, this course was the first course in software development. Therefore, our results may be quite different for intermediate to advanced developers who already have a cognitive basis for programming knowledge and may be more able to cope with, and take advantage of, differing personalities. Therefore, future research should certainly replicate our results with more advanced programming teams.

Another idea for future research would focus on defining the combination of diverse personalities to achieve the highest level of software development performance and the combination of common personalities to achieve the highest level of software development learning. This could allow organizations to maximize their possibility to achieve their desired outcome of learning or performance.

Another limitation of our research is that we identified only two types of personality clusters. This result was favorable for an initial experiment like ours. However, with greater participation, future research should identify more clusters of personalities and estimate their effects on various roles in a software development team (e.g. design, code, test).

Finally, it should be noted that our experimental design - although motivated by the software development context - may be applicable to a wide variety of engineering teams and other teams that depend on learning over time. Future research should measure additional variables that are more specific to individual domains.

\section{Conclusion}

In conclusion, managers and academic departments using team-based software development would benefit from measuring personalities and combining similar personalities to maximize effectiveness and learningat least in the early stages of a student's program or 
employee's career.

\section{References}

[1] A. Ahronson and J. E. Cameron, "The nature and consequences of group cohesion in a military sample", Military Psychology, 19 (2007), pp. 9.

[2] M. Alavi and D. E. Leidner, "Review: Knowledge management and knowledge management systems: Conceptual foundations and research issues", MIS quarterly (2001), pp. 107-136.

[3] D. J. Armstrong and B. C. Hardgrave, "Understanding mindshift learning: The transition to object-oriented development", MIS Quarterly, 31 (2007), pp. 453-474.

[4] L. G. Aspinwall, "Rethinking the role of positive affect in self-regulation", Motivation and Emotion, 22 (1998), pp. 1-32. [5] M. R. Barrick, G. L. Stewart, M. J. Neubert and M. K. Mount, "Relating member ability and personality to workteam processes and team effectiveness", Journal of applied psychology, 83 (1998), pp. 377.

[6] B. Barry and G. L. Stewart, "Composition, process, and performance in self-managed groups: the role of personality", Journal of Applied psychology, 82 (1997), pp. 62.

[7] D. J. Beal, R. R. Cohen, M. J. Burke and C. L. McLendon, "Cohesion and performance in groups: A meta-analytic clarification of construct relations", Journal of Applied Psychology, 88 (2003), pp. 989-1004.

[8] K. Beck, M. Beedle, A. Van Bennekum, A. Cockburn, W. Cunningham, M. Fowler, J. Grenning, J. Highsmith, A. Hunt and R. Jeffries, "Manifesto for agile software development", (2001).

[9] I. Blanchette and A. Richards, "The influence of affect on higher level cognition: A review of research on interpretation, judgement, decision making and reasoning", Cognition \& Emotion, 24 (2010), pp. 561-595.

[10] I. T. Boyle, The impact of adventure-based training on team cohesion and psychological skills development in elite sporting teams, Universal-Publishers, 2003.

[11] V. V. Busato, F. J. Prins, J. J. Elshout and C. Hamaker, "The relation between learning styles, the Big Five personality traits and achievement motivation in higher education", Personality and Individual Differences, 26 (1998), pp. 129140.

[12] L. F. Capretz, "Personality types in software engineering", International Journal of Human-Computer Studies, 58 (2003), pp. 207-214.

[13] CareerBuilder, "Overwhelming Majority of Companies Say Soft Skills Are Just as Important as Hard Skills, According to a New CareerBuilder Survey", http://www.careerbuilder.com/share/aboutus/pressreleasesdet ail.aspx ?ed=12/31/2014\&id=pr817\&sd=4/10/2014, April 10, 2014, Accessed on June 7, 2017.

[14] A. V. Carron, "Cohesiveness in sport groups: Interpretations and considerations", Journal of Sport Psychology, 4 (1982).

[15] A. V. Carron, M. M. Colman, J. Wheeler and D. Stevens, "Cohesion and performance in sport: A meta analysis", Journal of Sport \& Exercise Psychology, 24 (2002).

[16] A. V. Carron, W. N. Widmeyer and L. R. Brawley, "The development of an instrument to assess cohesion in sport teams: The Group Environment Questionnaire", Journal of sport psychology, 7 (1985).

[17] D. Cartwright, "The nature of group cohesiveness", Group dynamics: Research and theory, 91 (1968), pp. 109.

[18] J. F. Costello, Developing Team Cohesion: A Quasi-Field Experiment, DTIC Document, 2004.

[19] S. Cruz, F. Q. da Silva and L. F. Capretz, "Forty years of research on personality in software engineering: A mapping study", Computers in Human Behavior, 46 (2015), pp. 94-113. [20] S. S. Cruz, F. Q. da Silva, C. V. Monteiro, P. Santos and I. Rossilei, "Personality in software engineering: Preliminary findings from a systematic literature review", Evaluation \& Assessment in Software Engineering (EASE 2011), 15th Annual Conference on.

[21] B. De Raad and H. C. Schouwenburg, "Personality in learning and education: a review", European Journal of Personality, 10 (1996), pp. 303-336.

[22] A. Edmondson, "Psychological safety and learning behavior in work teams", Administrative science quarterly, 44 (1999), pp. 350-383.

[23] K. M. Eigel and K. W. Kuhnert, "Personality diversity and its relationship to managerial team productivity", (1996). [24] M. D. Ensley and A. W. Pearson, "An exploratory comparison of the behavioral dynamics of top management teams in family and nonfamily new ventures: Cohesion, conflict, potency, and consensus", Entrepreneurship Theory and Practice, 29 (2005), pp. 267-284.

[25] L. Festinger, K. W. Back and S. Schachter, Social pressures in informal groups: A study of human factors in housing, Stanford University Press, 1950.

[26] C. Fornell and F. L. Bookstein, "Two structural equation models: LISREL and PLS applied to consumer exit-voice theory", Journal of Marketing Research, 19 (1982), pp. 440452.

[27] C. Fornell and D. F. Larcker, "Evaluating structural equation models with unobservable variables and measurement error", Journal of Marketing Research, 18 (1981), pp. 39-50.

[28] L. R. Goldberg, J. A. Johnson, H. W. Eber, R. Hogan, M. C. Ashton, C. R. Cloninger and H. G. Gough, "The international personality item pool and the future of publicdomain personality measures", Journal of Research in Personality, 40 (2006), pp. 84-96.

[29] Y. Gong, J.-C. Huang and J.-L. Farh, "Employee learning orientation, transformational leadership, and employee creativity: The mediating role of employee creative selfefficacy", Academy of management Journal, 52 (2009), pp. 765-778.

[30] J. Gorgone, G. B. Davis, J. S. Valacich, H. Topi, D. L. Feinstein and H. E. Longenecker, "IS 2002 model curriculum and guidelines for undergraduate degree programs in information systems", Communications of the Association for Information Systems, 11 (2003), pp. 1.

[31] M. Gu and X. Tong, "Towards hypotheses on creativity in software development", International Conference on Product Focused Software Process Improvement.

[32] T. Halfhill, E. Sundstrom, J. Lahner, W. Calderone and T. M. Nielsen, "Group personality composition and group effectiveness: An integrative review of empirical research", Small group research, 36 (2005), pp. 83-105.

[33] R. L. Helmreich, "Cockpit management attitudes", 
Human factors, 26 (1984), pp. 583-589.

[34] B. A. Hennessey and T. M. Amabile, "Creativity", Annual Review of Psychology, 61 (2010), pp. 569-598.

[35] J. Highsmith and A. Cockburn, "Agile software development: The business of innovation", Computer, 34 (2001), pp. 120-122.

[36] R. Hirschheim and H. K. Klein, "A glorious and not-soshort history of the information systems field", Journal of the Association for Information Systems, 13 (2012), pp. 188.

[37] R. Hirschheim, C. Saunders and D. Straub, "Historical Interpretations of the IS Discipline: An introduction to the special issue", Journal of the Association for Information Systems, 13 (2012), pp. 1-8.

[38] G. Hirst, D. Van Knippenberg and J. Zhou, "A cross-level perspective on employee creativity: Goal orientation, team learning behavior, and individual creativity", Academy of management journal, 52 (2009), pp. 280-293.

[39] M. Hoegl, K. P. Parboteeah and C. L. Munson, "Teamlevel antecedents of individuals' knowledge networks", Decision Sciences, 34 (2003), pp. 741-770.

[40] T. A. Judge, J. E. Bono, R. Ilies and M. W. Gerhardt, "Personality and leadership: A qualitative and quantitative review", Journal of Applied Psychology, 87 (2002), pp. 765 780.

[41] H. J. Klein and P. W. Mulvey, "Two investigations of the relationships among group goals, goal commitment, cohesion, and performance", Organizational Behavior and Human Decision Processes, 61 (1995), pp. 44-53.

[42] J. A. LePine, B. R. Buckman, E. R. Crawford and J. R. Methot, "A review of research on personality in teams: Accounting for pathways spanning levels of theory and analysis", Human Resource Management Review, 21 (2011), pp. 311-330.

[43] P. B. Lowry and J. Gaskin, "Partial least squares (PLS) structural equation modeling (SEM) for building and testing behavioral causal theory: When to choose it and how to use it", Professional Communication, IEEE Transactions on, 57 (2014), pp. 123-146.

[44] S. B. MacKenzie and P. M. Podsakoff, "Common method bias in marketing: causes, mechanisms, and procedural remedies", Journal of Retailing, 88 (2012), pp. 542-555.

[45] L. McLeod and S. G. MacDonell, "Factors that affect software systems development project outcomes: A survey of research", ACM Computing Surveys (CSUR), 43 (2011), pp. 24.

[46] B. Mullen and C. Copper, "The relation between group cohesiveness and performance: An integration", Psychological bulletin, 115 (1994), pp. 210.

[47] J. F. Nunamaker Jr, L. M. Applegate and B. R. Konsynski, "Facilitating group creativity: Experience with a group decision support system", Journal of Management Information Systems, 3 (1987), pp. 5-19.

[48] M. B. O'leary, M. Mortensen and A. W. Woolley, "Multiple team membership: A theoretical model of its effects on productivity and learning for individuals and teams", Academy of Management Review, 36 (2011), pp. 461-478.

[49] K. Payne, M. J. Keith, J. S. Babb and A. Spruill, "Development and Validation of the Information Systems Creative Self-Efficacy Scale", Hawaiian International Conference on System Sciences, Waikaloa, HI, January 3-6.
[50] M. A. Peeters, H. F. Van Tuijl, C. G. Rutte and I. M. Reymen, "Personality and team performance: a metaanalysis", European Journal of Personality, 20 (2006), pp. 377-396.

[51] P. M. Podsakoff, S. B. MacKenzie, J. Y. Lee and N. P. Podsakoff, "Common method biases in behavioral research: A critical review of the literature and recommended remedies", Journal of Applied Psychology, 88 (2003), pp. 879-903.

[52] A. W. Richter, G. Hirst, D. Van Knippenberg and M. Baer, "Creative self-efficacy and individual creativity in team contexts: Cross-level interactions with team informational resources", Journal of Applied Psychology, 97 (2012), pp. 1282.

[53] C. M. Ringle, S. Wende and J.-M. Becer, "SmartPLS 3", Boenningstedt: SmartPLS GmbH, http://www.smartpls.com/ (2015).

[54] R. H. Rutherfoord, "Using personality inventories to help form teams for software engineering class projects", $A C M$ Sigcse Bulletin.

[55] K. A. Schneewind and A. K. Gerhard, "Relationship personality, conflict resolution, and marital satisfaction in the first 5 years of marriage", Family Relations, 51 (2002), pp. 6371.

[56] J. Senécal, T. M. Loughead and G. A. Bloom, "A seasonlong team-building intervention: examining the effect of team goal setting on cohesion", Journal of Sport \& Exercise Psychology, 30 (2008).

[57] G. L. Stewart, M. Barrick and A. Ryan, "Toward an understanding of the multilevel role of personality in teams", Personality and work: Reconsidering the role of personality in organizations (2003), pp. 183-204.

[58] R. Tibshirani, G. Walther and T. Hastie, "Estimating the number of clusters in a data set via the gap statistic", Journal of the Royal Statistical Society: Series B (Statistical Methodology), 63 (2001), pp. 411-423.

[59] P. Tierney and S. M. Farmer, "Creative self-efficacy: Its potential antecedents and relationship to creative performance", Academy of Management Journal, 45 (2002), pp. 1137-1148.

[60] A. Tiwana and E. R. Mclean, "Expertise integration and creativity in information systems development", Journal of Management Information Systems, 22 (2005), pp. 13-43.

[61] D. Tjosvold, "The conflict-positive organization: It depends upon us", Journal of Organizational Behavior, 29 (2008), pp. 19-28.

[62] A. E. Van Vianen and C. K. De Dreu, "Personality in teams: Its relationship to social cohesion, task cohesion, and team performance", European Journal of Work and Organizational Psychology, 10 (2001), pp. 97-120.

[63] W. Q. Wang and I. Benbasat, "Trust in and Adoption of Online Recommendation Agents", Journal of the Association for Information Systems, 6 (2005), pp. 72-101.

[64] K. B. White and R. Leifer, "Information systems development success: Perspectives from project team participants", MIS quarterly (1986), pp. 215-223.

[65] D. Winsborough and T. Chamorro-Premuzic, "Great Teams Are About Personalities, Not Just Skills", https://hbr.org/2017/01/great-teams-are-about-personalitiesnot-just-skills, January 28th, Accessed on April 13th, 2017. 